\title{
التفسير العلمي في القرآن الكريم بين المؤيدين والمخالفين: دراسة تحليلية نقدية
}

\author{
عثمان \\ (كلية الشريعة والإقتصاد الإسلامي بجامعة ماتارم الإسلامية الحكومية \\ البريد الإلكتروني: daliminia@gmail.com)
}

Abstract: One of the patterns of Qur'an interpretation that develops widely in the last and current century is Tafsir al-'ilmiy. The pattern of Qur'an interpretation has been revealing opinion and argumentation that accept as well as reject it. The article is aimed at analyzing position of this pattern among the Qur'an interpreters, mufassirūn. The method used in this study is comparison analysis. The author concludes that, despite of controversies among the mufassirūn, there is a common intention and objectives they share. They find that Qur'an verses containing scientific signs, known as ayaat kawniyyah, must be considered to bear intrinsically guide to bumankind. The mufassirūn are obliged to find and elaborate the guide.

Abstrak: Salah satu di antara corak tafsir al-Qur'an yang berkembang dan mengundang perhatian, walau terdapat pro dan kontra di kalangan para pakar tafir, hingga sekarang adalah tafsir al-ilmiy. Baik pibak yang pro maupun yang kontra mengemukakan argumentasi masing-masing untuk memperkuat pendapatnya. Tulisan ini bertujuan untuk mengkaji kedudukan tafsir al-ilmy dan latar belakang terjadinya pro-kontra mengenai terhadapnya di kalangan para ulama' tafsir. Metode yang diguanakan dalam kajian ini adalah analisis perbandingan. Penulis menyimpulkan, baik kalangan ulama' yang pro maupun yang kontra terhadap tafsir al-ilmy pada hakekeatnya memiliki tujuan yang sama yaitu utuk menunjukkan bahwa ayat-ayat kawniah dalam al-Qur'an adalah sebagai petunjuk bagi umat manusia. Para mufassirun berkewajiban menemukan dan menjelaskan tentang petunjuk tersebut.

Keywords: tafsir al-ilmy, al-Quran, ulama klasik, ulama kontemporer, ayat kawniyyah 
وللتفسير مناهجها وألوانه المتعددة، وإن التوافق بين الحقائق العلمية والآيات القرآنية هو

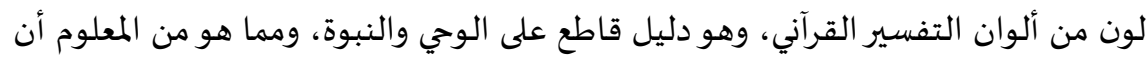
لغة اليوم هي لغة العلم والكشف والاختراع، فهي الأساس والمحور الرئيسي للتفاهم وتبادل

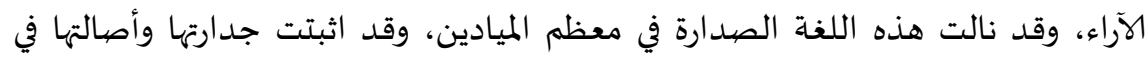
الوصول إلى الأهداف والغايات التي يصبو إليها كل طموح. والتفسير العلمي هو أحد فروع هذه اللغة النابعة من كتاب الله الذي لا يأتيه الباطل

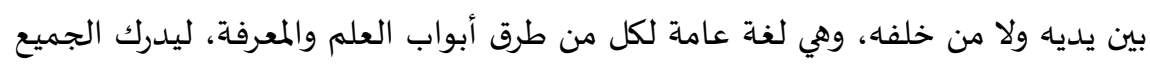
ذلك الدليل القاطع الذي يثبت بلا شك أن القرآن من عند مند الله.

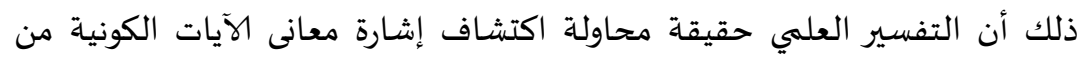
القرآن الكريم الذي يتعلق بظواهر الكون ثم يتصل بالحقائق العلمية التي لم تعرف فيها

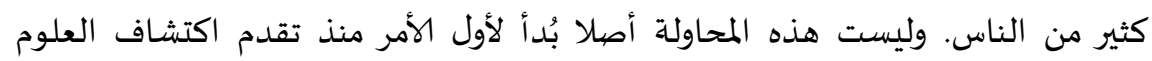

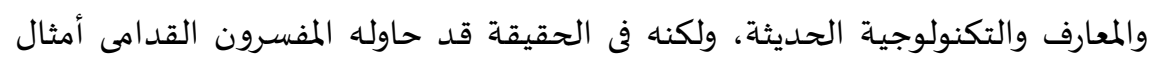
الغزالي وفخر الدين الرازي وجلال الدين السيوطي ومن سار نهجهم فى بحث ذلك منذ قرون ماضية قبل اكتشاف حقيقة العلمية الحديثة.

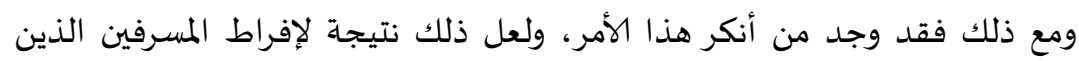
تجاوزوا الحد في الميل إلى التفسير العلمي للقرآن فكانت ردة الفعل المعاكسة المتمثلة في موقف المنكرين. ومن أجل ذلك يتناول هذا البحث الإختلاف أراء العلماء بين المؤيدين للتفسير العلمي و آراء من يخالفه من خلال هذا الإختلاف على مدى قوة الإختلاف فيه وسبيل الخروج منه، وذلك ليرى من ذلك القبول والرد من خلال ما كتبوا وقالوا ليكون ذلك أقرب

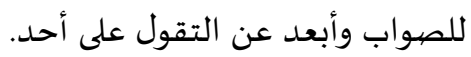

\section{التفسير العلمي ومكانته}

كان من البديهي أن يعلم أن التفسير العلمي يتكلم عن المصطلحات العلمية في

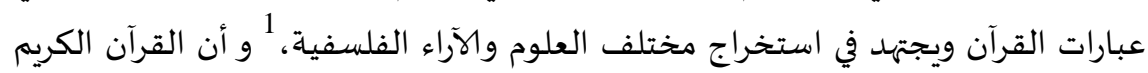
قد تعرض لكثير مظاهر هذا الوجود الكونية، فتناول خلق الإنسان، وتكوين الأرض وخران

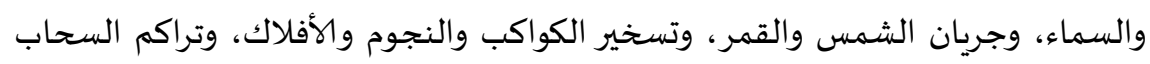

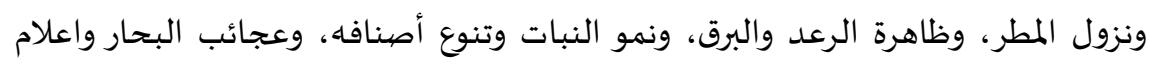

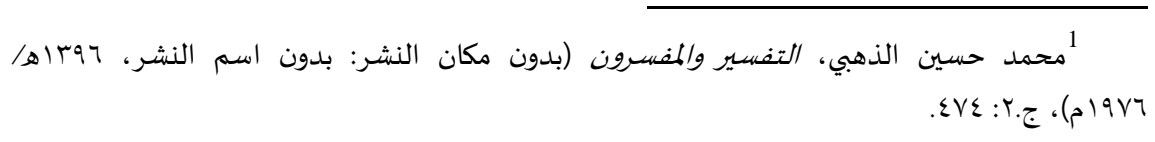


الطريق، والجبال الرواسي على هذه الأرض، وأطوار الأجنة في بطون أمهاتها، إلى غير ذلك مما يتناوله علماء الكون بالتمحيص والبيان وما هو موضوع بحوثهم ومحل عينايتهم وتجاربهم.

وقد وقع هذا النوع من التفسير، واتسع القول في احتواء القرآن كل العلوم ما كان منها وما يكون، فالقرآن في نظر أصحاب هذه الطريقة يشمل إلى جانب العلوم الدينية الاعتقادية والعملية، وسائر علوم الدنيا على اختلاف أنواعها، وتعدد ألوانها. 3 ومن هنا يعرف أن القرآن الكريم حين أشار إلى هذه النوامس الكونية والمظاهر

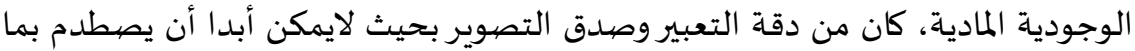
يكشف العقل الإنساني عنه في آطواره المختلفة من حقائق هذه العلوم ومقرراتها، وخصوصا إذا لاحظنا أن هذه المقررات العلمية تنقسم إلى قسمين: قسم تظاهرت عليه الأدلة وتوافرت الحجج حتى كاد يلحق بالبديهات و قسم لا زال في طور البحث العلمي، وكل الذي بين يدي العلماء الكونيين منه فروض تؤيدها بعض القرائن التي لم ترق إلى مرتبة

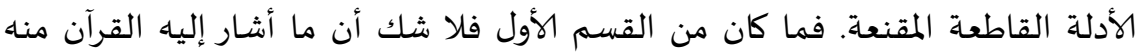

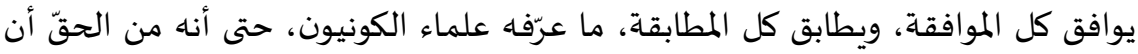

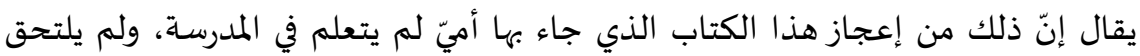
بجامعة من الجامعات، ومن أمثلة ذلك إشـارة إلى أطوار الجنين، وتلقيح الرياح، وتكوين السحاب وصلته با الرياح. وتفسير الآيات الكونية من القرآن ، إذن، مهمة وجليلة بجانب تفسير الآيات الأخرى

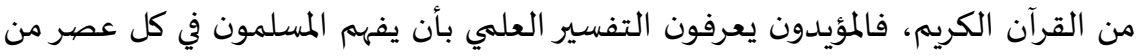
العصور النص القرآنيي حسب عقولهه، وحسبما تزودت تلك العقول من ثقافات علمية

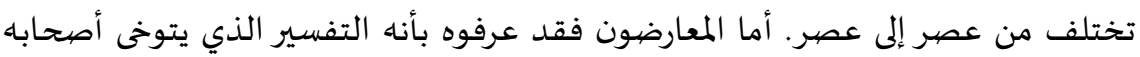
إخضاع عبارات القرآن للنظريات والاصطلاحات العلمية، ويذل أقصى الجهد في استخراج نختلق مسائل العلوم والآراء الفلسفية منها.

\section{موقف العلماء حول التفسير العلمي}

وقد اختلف العلماء حول التفسير العلمي إلى الاتجاهين ما بين المؤيدين والمعارضين، وسيفصل هذين الاتجاهين على حدة، وذلك كما يلي:

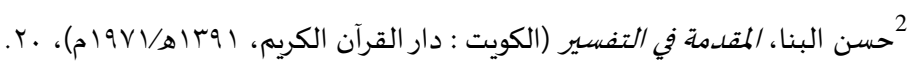

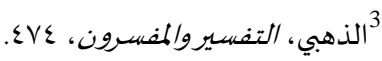

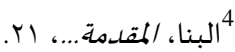


الاتجاه الأول: المؤيدون لتفسير العلمي من العلماء

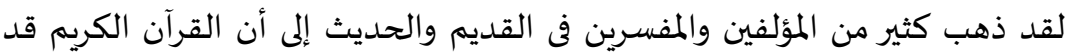

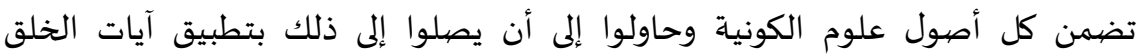
والتكوين وما إلهها على ما عرف الناس من هذه العلوم. فمن المفسرين القدامى عبد الله

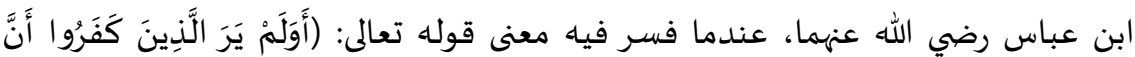

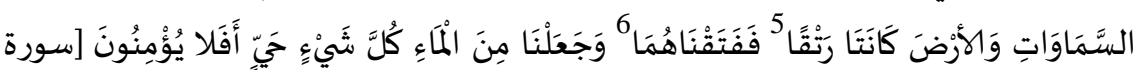
الأنبياء (21): 30]).

ونقل الشيخ الصابوني رواية عن عبد الله ابن عباس رضي الله عنهما، حيث يقول في

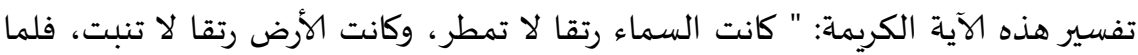
خلق الأرض أهلا، فتق السماء بالمطر وفتق الأرض بالنبات". 7 وعلق الشيخ الصابوني هذا التفسير حيث يقول: هذا التفسير جميل وحسن ويكون

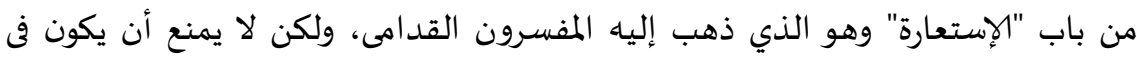
القرآن بعد هذه الروائع العلمية التي كشف عنها العلم الحديث، فالقرآن حمال وجوه

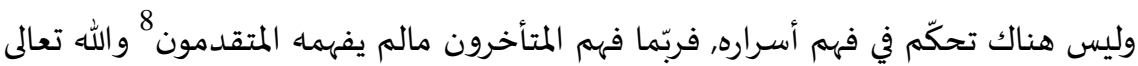

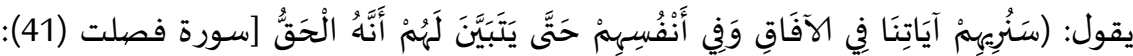
53). فلعلّ هذا، من الآيات التي اطلعهم الله عليها في القرن الأخير". ومثل هذا سار عليه الإمام الغزالي رحماه الله (المتوفى 505 هـ/1111 م) في تفسيره "جواهر القرآن". ومما يدل على ذلك أنه رحماه الله قرّر لكيفية انشعاب العلوم الدينية كلها

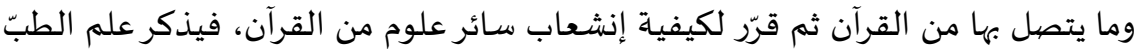
والنجوم، وهيئة العالم، وهئية بدن الحيوان، وتشريح أعضائه, وعلم السحر، وعلم الطلسمات وغير ذلك حيث يقول: "ووراء ما عددته علوم أخرى، يُعلم تراجمه ولا يخلوا

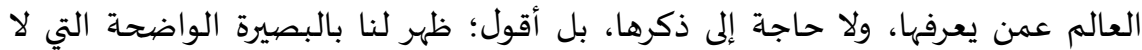
يتمارى فيها أن في الإمكان والقوة أصنافا من العلوم بعد لم تخرج من الوجود، و و إن كان في

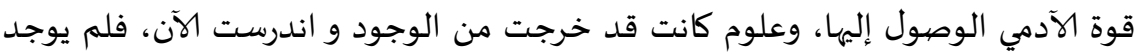
في هذه الأعصار على بسيط الأرض من يعرفها، وعلوم أخرى ليست في قوة البشر أصلا

ألرتق هنا بمعنى الضم والإلتحام، ينظر: محمد على الصابوني، التبيان في علوم القرآن (بيروت: دار الإرشاد، 1970)، 131.

6 الفتق بمعنى الفصل بين الشيئين، المصبلدر السابق، 1310، 131. 7الصابوني, التبيان...، 132. وينظر: أبو الفداء ابن كثير, تفسير القرآن العظيم (سنقافورة-جدة: الحرمين، بدون سنة) ج. 2، 187.

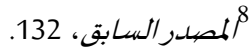


إدراكها والإحاطة بها، ويخطئ بها بعض الملائكة المقربين، فإنّ الإمكان في حق الآدمي محدود، والإمكان في حق الملك محدود إلى غاية من النقصان، وإنما الله سبحانه وتعالى هو الذي لا يتناهي العلم في حقه".

ثم أضاف الغزالي " ثم هذه العلوم ما عددنا ومالم نعددها، ليست أوائلها خارجها من في

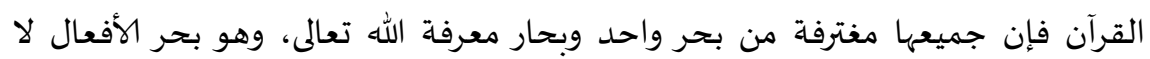

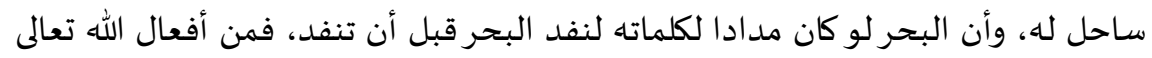

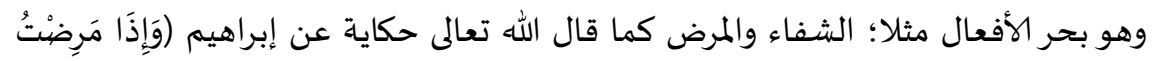
فَهُوَ يَشْفِينِ [سورة الشعراء (26): 80]). وهذا الفعل الواحد لا يعرفه إلا من عرف علم الطب بكماله، إذ لا معي للطب إلإين معرفة المرض بكماله وعلامته، ومعرفة الشفاء

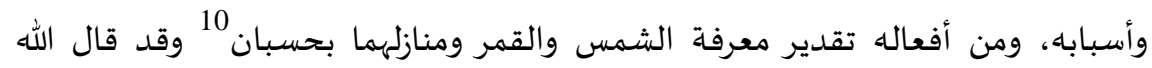

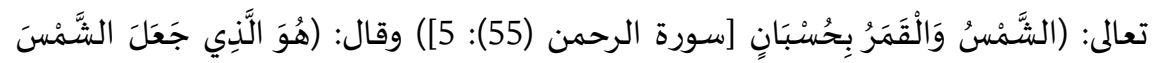

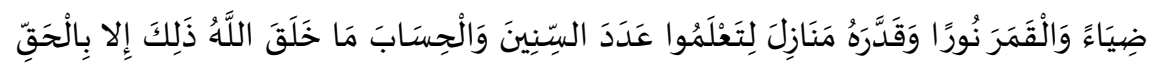

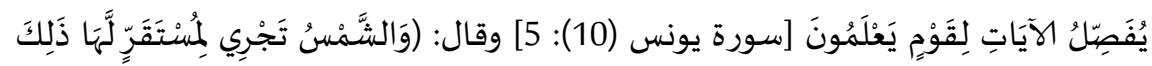

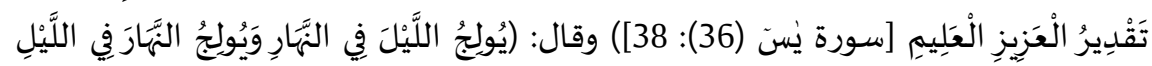

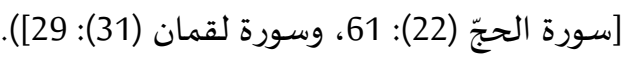

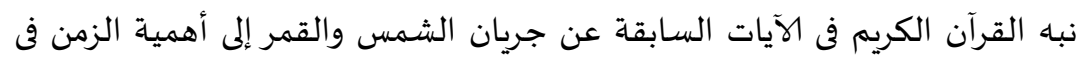

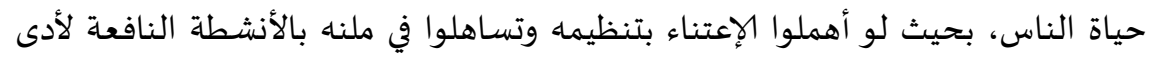

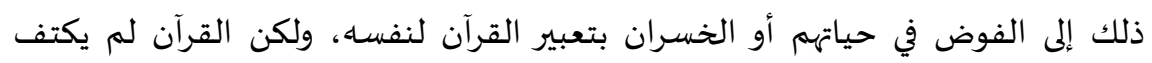
بالتنبيه فقط، بل وضع أيضا معالم أساسية في كيفية ضبطه وتنظيماه باستلفات الأنظار إلى الأجرام السماوية خصوصا للشمس والقمر، فأخبر أن حركات هذين النيرين قابلة لتنبؤ لإنها يحكمها قانون ثابت. 11

قال الإمام الغزالي رحمه الله بالنسبة إلى تفسير الآيات السابقة؛ ولا يُعرف حقيقة الشمس والقمر بحسبان وخسوفهما، وولوج الليل في النهار وكيفية تكور أحدهما على الآخر

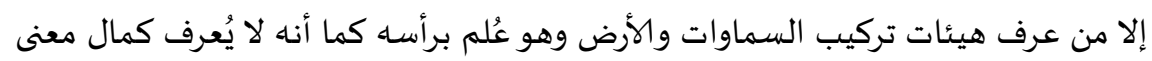

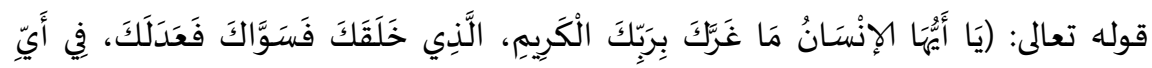

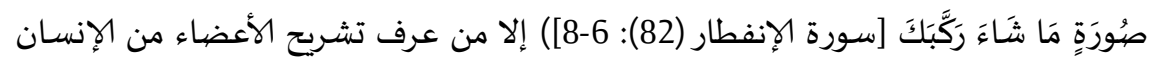
أبو حامد محمد بن محمد الغزالي، جواهر القرآن، (كردستان: بدون اسم النشر، 1329 هـ)، 31-

$$
\text { 10 الغزالي، الجواهر...، }
$$

11 شمس الأنوار، الجوانب الشرعية والفرالفهية لوضيع التقويم الإسلامي العالمي، الجامعة مجلة 
ظاهرا وباطنا وعددها وأنواعها وحكمتها ومنافعها. وقد أشار فى القرآن الكريم في مواضع إليها، وهي من علوم الأولين والآخرين، وفى القرآن مجامع علم الأولين والآخرين. وكذلك لا

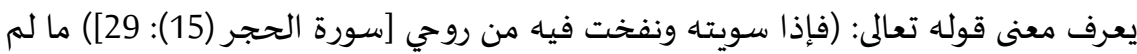
يعلم التسوية، والنفخ والروح، وورائها علوم غامضية يغفل عن طلبها أكثر الخلق، وربما لا لإئل يفهمونها إن سمعوها من العالم بها ولو ذهبت أفصل ما تدل عليه آيات القرآن من تفاصيل الأفعال لطال، ولا يمكن الإشارة إلا إلى مجامعها. فتفكر فى القرآن، والتمس غرائبه

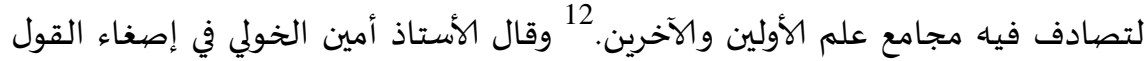
الغزالي: "الحق أن كتاب الدين لايُعنى بهذا من حياة الناس، ولا يتولاه بالبيان، ولا يكفيهم مؤونته حتى يلتمسوه عنده ويعدوه مصدرا فياه". 13 ويليه بعد الغزالي العلامة السيوطي رحمه الله (المتوفى 911 هـ) بقرون وينحوا منحى الغزالي فى القول بتفسير العلم ويقرر ذلك بوضوح وتوسع في باب مخصوص "العلوم

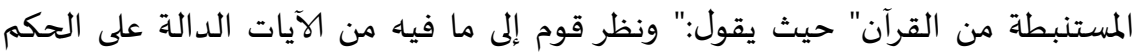
الباهرة في الليل والهار والشمس والقمر ومنازله والنجوم والبروج وغير ذلك فاستخرجوا منها علم المواقيت.

هذه الفنون التي أخذتها الملة الإسلامية منه وقد احتوى على علوم أخرى من علوم الأوائل مثل الطب والجدل والهيئة والهندسة والجبر والمقابلة النجامة وغير ذلك. أما الطب فمداره على حفظ نظام الصحة واستحكام القوة وذلك إنما يكون باعتدال المزاج بتفاعل كيفيات المتضيادة وقد جمع ذلك في آية واحدة وهي قوله تعالى: (وَكَانَ بَيْنَ ذَلِكَكَ قَوَامًا [سورة الفرقان (25): 67]) ومن ذالك يعرف فيه بما يفيد نظام الصحة بعد اختلاله

$$
\text { وحدوث الشفاء للبدن. } 14
$$

ومن الآيات التي دلّت على أن فى القرآن علوما كثيرة يحتاج إليها الإنسان، قوله تعالى:

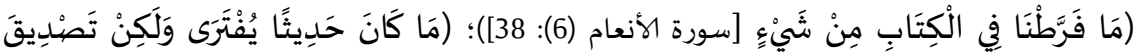

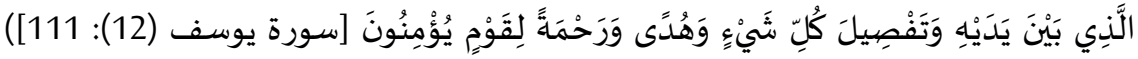

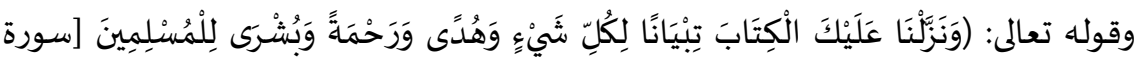
النحل (16): 289])

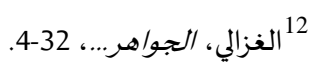

13 أحمد الشرباصي، قصرة التفسير (القاهرة: دار القلم، 1962)، 126.

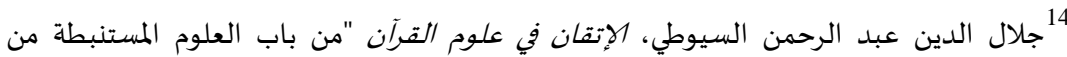

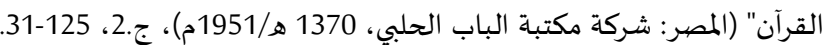

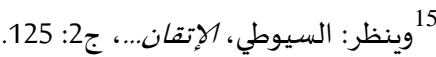


وكذلك أضاف السيوطي في كتابه الآخر حيث بين أن القرآن مشتمل على كل العلوم

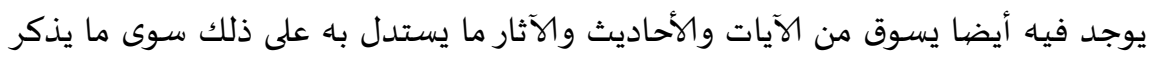

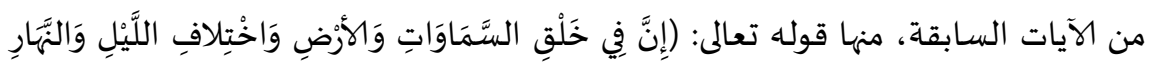

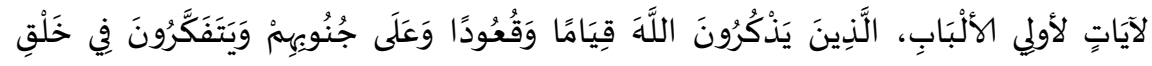

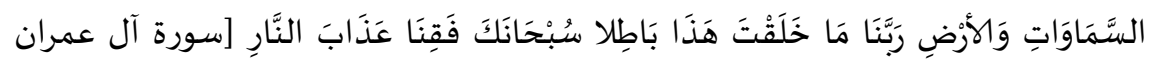

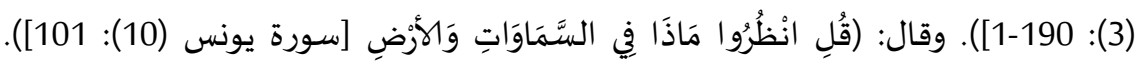

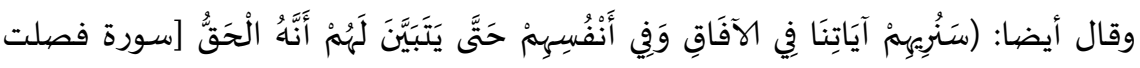

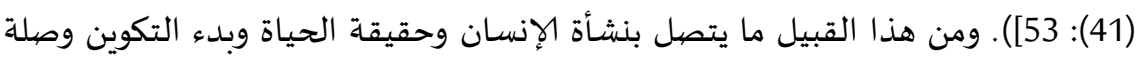

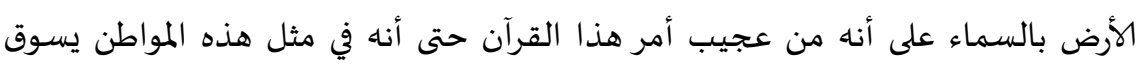

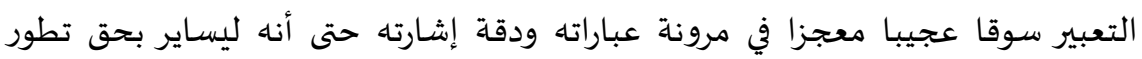
العقل الإنساني في كل زمان ومكان. 16

و من الآثار التي يسوقه لنصر رأيه على أهمية تطور التفسير العلمي عند السيوطي ما فال أخرجه سعيد بن منصور عن ابن مسعود رضي الله عنه أنها قال: "من أراد العلم فعليه بالقرآن فإن فيا خبر الأولين و الآخرين" وما أخرجه ابن أبي حاتم عن ابن مسعود رضي الله الله

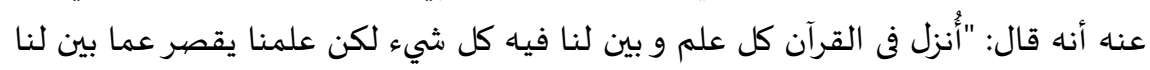
فى القرآن". ثم ذكر في كتابه "الإكليل" بعد أن يسوق هذه الأدلة يذكر فيه بعض العلماء أنها

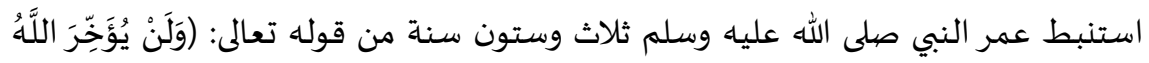

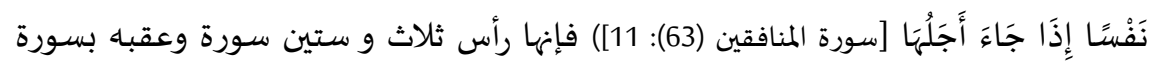

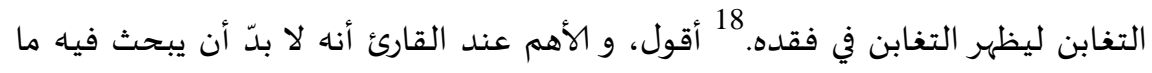
العلاقة بين عمر النبي صلى الله عليه وسلم و رقم السورة التي كتب في القرآن من الناحية

العلمية؟

و من علماء عصر الحديث الذي أيد هذا النوع من التفسير، هو الشيخ محمد علي

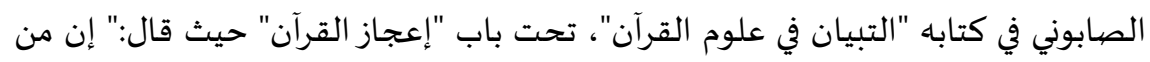
وجوه إعجاز القرآن تلك الإشارات الدقيقة إلى العلوم الكونية التي سبق إليها القرآن قبل أن تكشفها العلم الحديث، ثم عدم تعارضها مع مايكشفه العلم من نظريات علمية

16 جلال الدين عبد الرحمن السيوطي، الإكليل في استنباط التننيل (المصرر: شركة مكتبة البابي

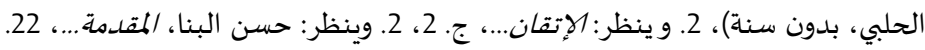
17 المصلدر السابق، 2. وينظر: الإتقان...، ج. ج. 2، 2126.

$$
\text { 18 السيوطي، الإكليل...، } 2 .
$$


حديثة، و قد أشـار القرآن الكريم إلى هذه الناحية من نواحى الإعجاز بقوله جل شأنه:

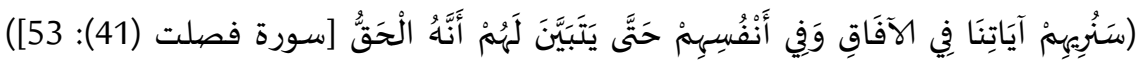

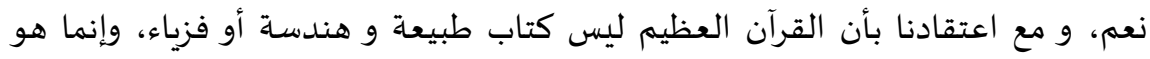
كتاب هداية و إرشاد وكتاب تشريع وإصلاح، ولكن مع ذلك لم تخل آياته من الإشارات الدقيقة والحقائق الخفية، إلى بعض المسائل الطبيعية والطبية والجغرافية. 19 ثم قال الصابوني " وما ورد إليه القرآن من آيات الكونية كله، لا يتعارض مع ما أظهيه أظهر عليه النظريات العلمية الحديثة، وهي نظرية علمية عن وحدة الكون [سورة الأنبياء (21): 30، و سورة فصلت (41): 53]، و نشأة الكون [سورة فصلت (41): 11]، وتقسيم الذرة [سورة سباء (34): 3؛ وسورة الزلزلة (99): 7-8]، ونقص الأوكسجين [سورة الأنعام (6):

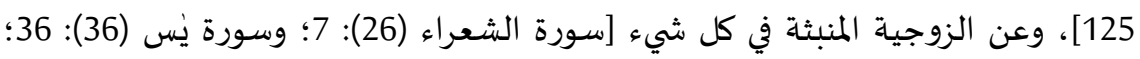
وسورة الذاريات (51): 49]، وأغشية الجنين [سورة الزمر (39): 6]، والتلقيح بواسطة الرياح [سورة الحجر (15): 22]، والحيوان المنوي [سورة العلق (96): 1-2]، واختلاف بصهمات الإنسان

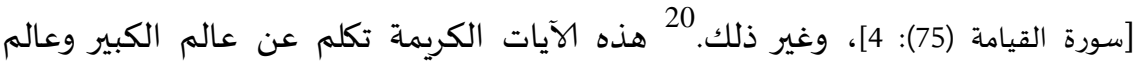
الصغير.

و ممن ذهب إلى التفسير العلمي أيضا الدكتور محمد جمال الدين إلفندي حيث تكلم

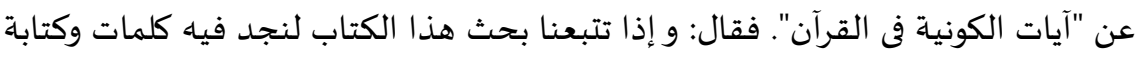
مهمة وهي علاقة وميثاقة قوية بين القرآن والعلم، ويتجلى فى القرآن بين الحق القاطعة القانية والعلم الظنية، والمسئلة الأساسية التي تتعلق بالكونية وحسن التعبير في إشارات آيات

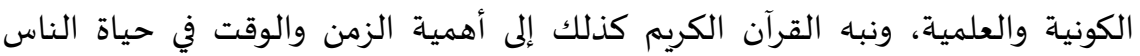
جميعا. وقال الشيخ أحمد الشرباصي: نستطيع أن جزم باه هو أن القرآن الكريم لم يوجد فياه نصّ من النصوص يناقض حقيقة علمية ثابتة، وهذه ناحية من نواحي إعجازه، كما أن الذي أشار إليه من الحقائق العلمية يعدّ أيضا دليلا من دلائل هذا الإعجاز، وهذا

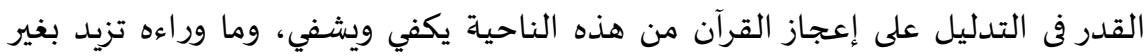
يقين، وتعريض للنص القرآني لبليلة الآراء والنظريات. 22

$$
\text { 19 الصابوني، التبيان...، 126-7 }
$$

${ }^{21}$ Muhammad Jamaluddin Elfandi, Al-Qur'an tentang Alam Semesta, ter. Abdul Bar Salim (Jakarta: Sinar Grafika, 2004), 1-113.

$$
\text { 22 الشرباصي، القصة.... } 127 .
$$


و من هنا يعلم أن موقف المؤيدين من العلماء في تفسير آيات الكونية لعلّ لاعتناء و التفات نظر للقارئ والسامع، ليزداد إيمانا لمن آمن بالقرآن من قبل، وليلتفت النظر إليه

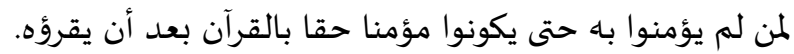

\section{الا تجاه الثاني المخالفون من العلماء}

من المعلوم أن التفسير هو كيفية لاكتشاف معنى كلام الله عزّ وجلّ المنزّل على نبيه صلى الله عليه وسلم وذلك حسب طاقة البشرية، اعتمادا على ما شُرط فياه وقواعده التي اتفق عليها علماء التفسير، منهم من فسر القرآن كله ترتيبا آية ثم آية من أول سورة الفاتحة إلى آخر سورة الناس تحليلية، ومنهم من فسره إجمالية، ومنهم من سلكه

$$
\text { موضوعية على حسب حاجة البشر. }
$$

و إذا كانت فكرة التفسير العلمي قد راجت عند بعض المتقدمين، كما قاله الشيخ

الدكتور محمد حسين الذهبي، و ازدادت رواجا عند بعض المتأخرين، فإنها لم تلق رواجا

عند بعض العلماء الأقدمين، كما أهها لم تلق رواجا عند بعض المدادين ألمأخرين منهم أيضيا. 23 نعم، كما تقدم بجانب من أيّد، يوجد أيضيا من خالف من علماء التفسير العلمي. و

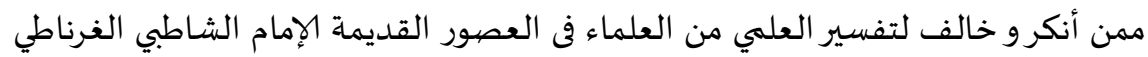
رحماه الله (المتوفى 790 هـ/1388 م) و ذكر من العلوم الصحيحة التي كان للعرب اعتناء بها مناء

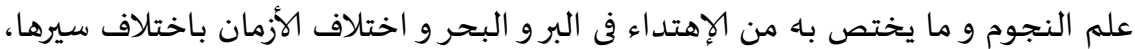

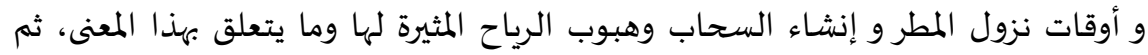
قال الشاطبي كل هذا مقرر في أثناء القرآن الكريم في مواضع كثيرة. وذكر علم الطب وبين

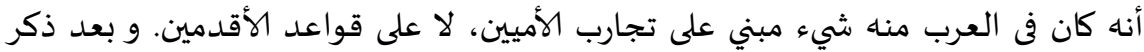
هذه العلوم، أوضح الشاطبي، أن الشريعة جاءت في تصحيح ما صحت ملئ وإبطال ما أبطلت، قد عرضت من ذلك إلى ما تعرفه العرب من العلوم ولم تخرج عما الفوه، ويتوجه باللوم إلى ما أضافوا للقرآن كل علوم الأولين والآخرين، وقال: إن كثيرا من الناس تجاوزوا في من فئ الدعوى على القرآن الحد، فأضافوا إليه كل علم يذكر للمتقدمين والمتأخرين من علوم

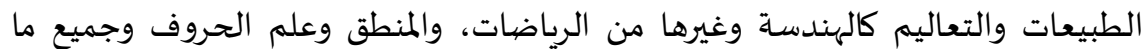

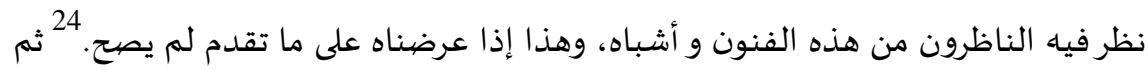
يصحح الشاطبي رأيه هذا ويحتج له بما عرف من السلف من نظرهم في القرآن فيقول: إن

$$
\text { 23 الذهبي، التفسير.... } 485 .
$$

24أبو إسحاق إبراهيم بن موسى الشاطبي الغرناطي، الموافقات (بدون مكان النشر: دار الفكر 
السلف الصالح من الصحابة والتابعين ومن يليهم كانوا أعرف بالقرآن وبعلومه وما أودع تمعا فيه، ولم تبلغنا أنه تكلم أحد منهم في شيء من هذا المدعى سوى ما تقدم، و ما ثبت فيه

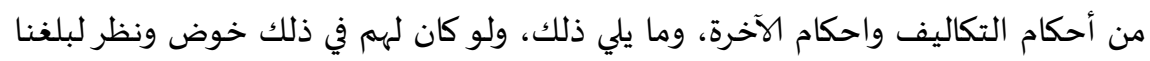

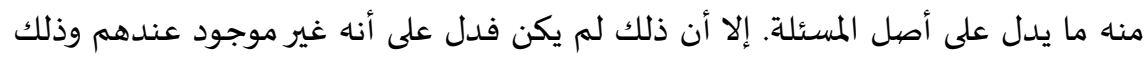

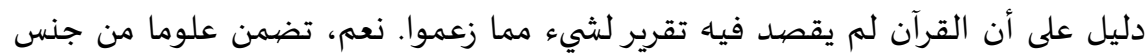
علوم العرب أو ما ينبنى على معهودها مما يتعجب منه أولوا الألباب، ولا تبلغه إدركات

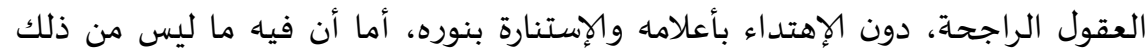

وبعد تصريح المزلق عند بعض المفسرين، أخذ الشاطبي في ذكر ما استند إلههم أرباب

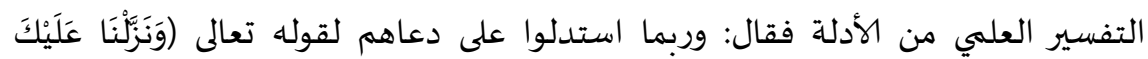

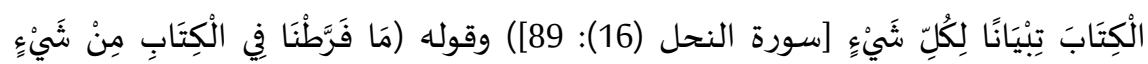
[سورة الأنعام (6): 38]) ونحو ذلك، وبفواتح السور، وهي مما لم يعهد عند العرب، وبما نقل عن الناس فيها، وربما حُكي من ذلك عن علي ابن طالب رضي الله عنه وغيره أشياء. 26

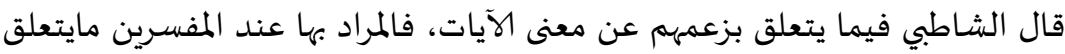
هها للتكليف و التعبد، أو المراد بالكتاب في قوله "ما فرطنا في الكتاب من شيء" هو اللوح المحفوظ ولم يذكروا فيها ما يقتضي تضمنها لجميع العلوم النقلية والعقلية. 27 ومن العلماء الأخير الذي أنكر هذا اللون من التفسير الشيخ حسن الثن البنا، قال رحمـه

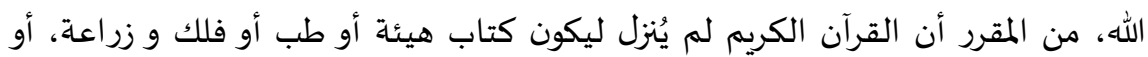
صناعة، ولكنه كتاب هداية أو إرشاد وتوجيه اجتماعي إلى أمهات المناهج الإجتماعية التي

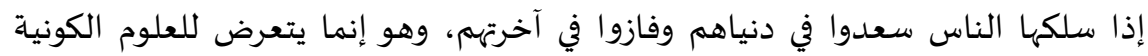

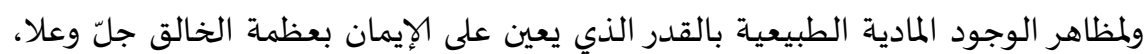

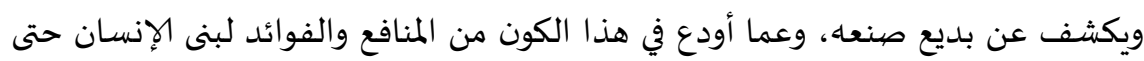
ييسر لههم بذلك طرائق الإهتداء إلى الإستفادة من هذه الخيرات في الأرض وفى السماء وفيما

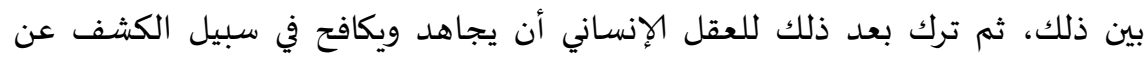

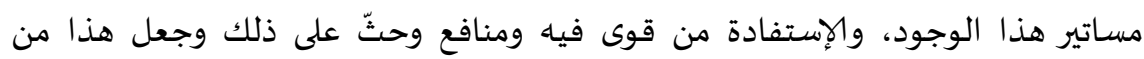
أفضل العبادة وأعلى أنواع ذكر الله تعالى. 28

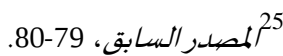

26 الشاطبي، الموافقات، ج. 2، 80.

$$
\text { 27 }
$$

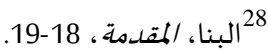


ومن العلماء من يرى أن القرآن الكريم قد تضمن كل أصيول العلوم الكونية وحاولوا أن يصلوا إلى ذلك لتطبيق آيات الخلق والتكوين وما إليها على ما عُرف الناس من هذه إنه العلوم، وهو جهد مشكور ولا شك، ولكنها تكليف بما لم يكلفنا الله فيه قد يصل في كثير النه

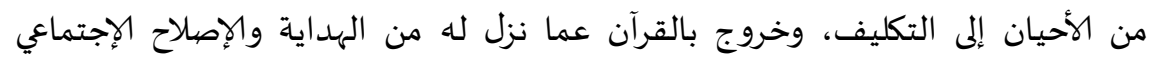
وتقرير قواعدهما في النفوس والمجتمعات، وتعرضوا لمعاني كتاب الله تبارك وتعالى لاختلاف

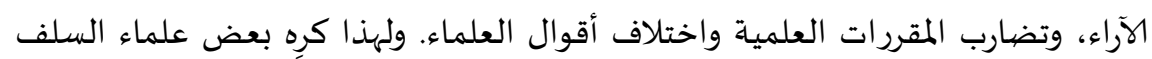

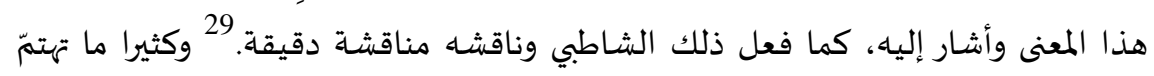
هذه الآيات بالحث على التعقل والتفكر والنظر والتدبر، إشـارة إلى أن القرآن الكريم لم يقصيد بهذا التعرض و تقرير أصول هذه العلوم أو تناول فروعها، ولكنه إنما قصيد إلى الهداية وتوجيه الأنظار والنفوس إلى ما تدل عليه من عظمة الخالق وفائدة المخلوقات. 30 وقد سار إلى ما سار إليه حسن البنا الشيخ أمين الخولي وهو من المفسرين المعاصير حيث أكد أن لون تفسير العلمي لله نقاط ضعيفة من ثلاثة نواحي: الأول من ناحية اللغوية، والثاني من ناحية الأدبية والثالث من ناحية العقائدية. فأما من الناحية اللغوية فإن الاصطلاحات التي تستخدم فيه لا يتناسب مع تاريخ اللغة نفسها و المصطلحات القرآنية المستخدمة فيها. وأما من الناحية الأدبية فإنه تبين أن لون هذا التفسير لا لإهيخ يتناسب حقيقة. مع أن نزول القرآن في القرن السـابع من ملادية يهدف إلى العرب خاصية.

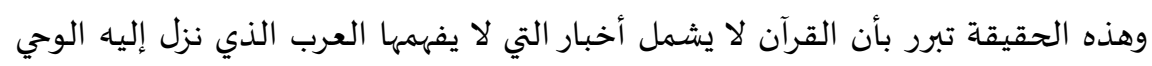
مثل الاصطلاحات والمعلومات الجديدة والعلوم اللتى عرف بعد نزول الوحي من بعيد. وأما

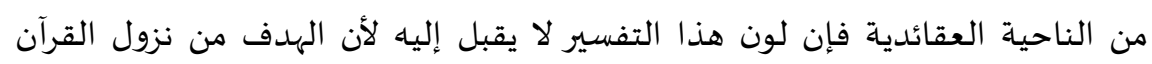
توصيل النصائح الدينية وعلى هذا يعتبر أنه ليس له صلة بالنظرية الكونية والعلوم خاصهة.وأن القرآن كتاب هداية الذي لا يمكن ان يتناسب دائما مع النظريات والتجريبيات

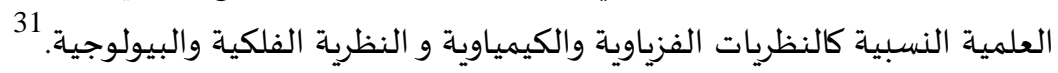

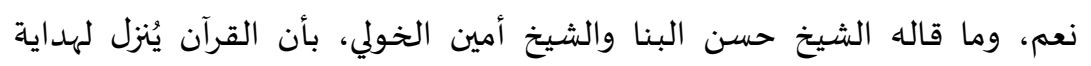
الناس، لا ننكر عليه ونعترف أنه كان ذلك من ناحية، ولكن من ناحية أخرى وعليه قد أند يكون القارئ أو السامع يحتاج إلى دليل وبرهان ساطع على ما قُرأ وما سُمع من القرآن،

$$
\begin{aligned}
& \text { 29 29 مصلدر السابق، 19-20. } \\
& \text { 30 }
\end{aligned}
$$

${ }^{31}$ Fakhruddin Faiz, Hermeneutika al-Qur'an, (Jogjakarta: Elsaq, 2011), 180-181.

وينظر: أمين الخولي، منهج التجديد في النحوي والبلاغة والتفسيروالأبب (القاهرة: الهيئة المصرية العامة 
ولذلك فلا بدّ أن نكتشف من جهة علمياة، سواء على سبيل الإستقراء أو التجربية أو بتصريح علمي، ويتعلق بذلك ما في معنى قولهم "ليس الخبر كالمعاينة أو العيان". 32 هذه

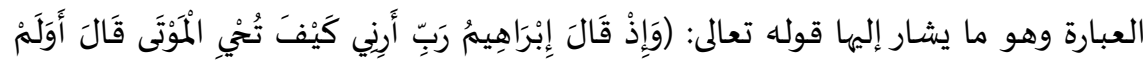

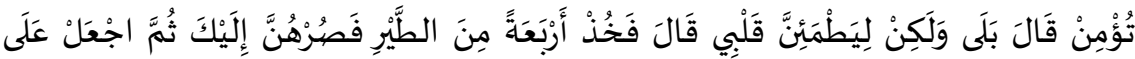

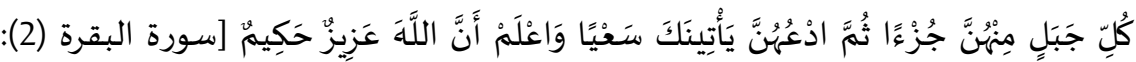

ويفهم مما سبق، أن من العلماء من أنكر تفسير الآيات الكونية، لعل نظرهم في هذا هو تخوفهم ممن حاولوا تفسير الآيات الكونية، من انصراف القارئ عن مقصيود أساسي من مني من نزول القرآن، وهو هداية للناس. ومن هنا يتبين أن بين المؤيدين والمخالفين في موقفهم للتفسير الآيات الكونية له هدف واحد، وهو ليؤكد مكانة القرآن هداية للناس ومصالح الناس وسعادتهم في الدارين.

ومن المستحسن في هذا المقام أن نصرح بعض آراء المفكرين الإندونيسيين وهو من

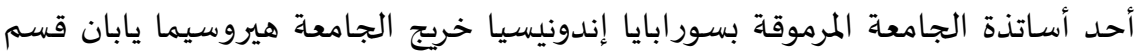
الفيزياء حيث إنه يعترض على التفسير العلمي الذي نهج إليه بعض المفسرين المعاصرين، وهو يرى أن تفسير القرآن بالعلوم الحديثة كانت في غاية الخطورة لأن العلوم الكونية -

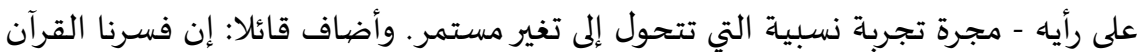

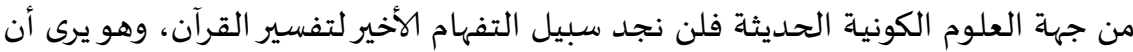

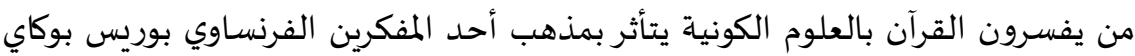
(الذي فسر كلام الله باطلاقه، و بمنهج علمي نسبي دون الاعتماد على (Maurice Bucailism) أسس ودليل قاطع. ثم يقول: إن هذا المنهج إن طبق لايجد سبلا بل يكون في غاية الخطورة، وأن يجعل عوام الناس يلخبطون بهذا التفسير العلمي بل لا يصل إلى الغاية الأسسى من المقصود الأصلي للقرآن 33

ورد أغوس مصطفى ماذهب إليه خبير الفيزياء وهو خريج جامعة هيروسيما بقوله :

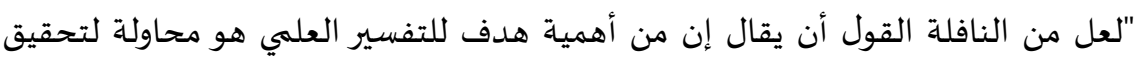

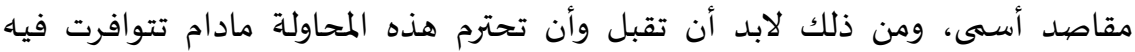

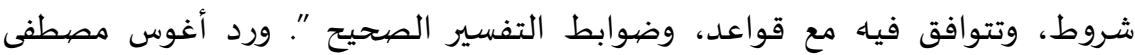
ماذهب إليه خبير الفيزياء وهو خريج جامعة هيروسيما بقوله : " لعل من النافلة القول

32 مناع القطان، مباحث في علوم القرآن (بيروت: الشركة المتحدة للتوزيع، 1393 هـ/1973 م)، 286.

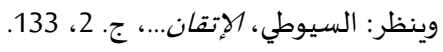

${ }^{33}$ Agus Mustafa, Pusaran Energi Ka’bah (Surabaya: Padma Press, t.th.), 13. 
أن نقول إن من أهمية هدف للتفسير العلمي هو محاولة لتحقيق مقاصد أسمى، ومن ذلك

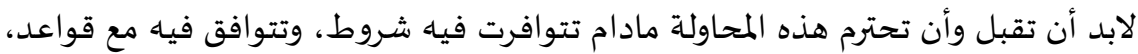
وضوابط التفسير الصحيح ". وما قدمه المفسرون من محاولة لتفسير القرآن العظيم يعتبر محاولة نسبية فحسب، لأنه قد يتأثر المفسرون بما لديهم من التخصصيات العلمية. فأهل

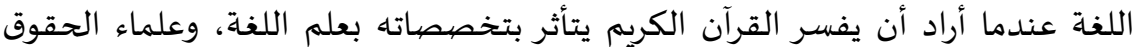

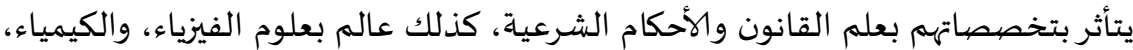
والهندسة وغيرها يتأثر بمالدياه من تخصصياته بهذه العلوم 34. ومما يلفت النظر أن الله تعالى لا يفرق ما بين الشريعة والمعرفة، بل كلاهما متحدان في اعطاء صور عن القرآن، بل - كما أفاد إليه أغوس - إن الدين والعلم كانا على إنى مواقع واحدة في القرآن، بمعنى أههما يعرفان عن وحدينته تعالى وبن ووجوده، وبالتالي كانا

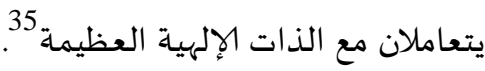

ومن هنا يمكن أن يجزم أن القرآن لم يجد فيه نص متناقض إلا يمكن أن يفسر نسبيا معانياه إلى معان متعددة حسب قدرة المحاولة لفهم كلام الله من حيث هذا وذاك

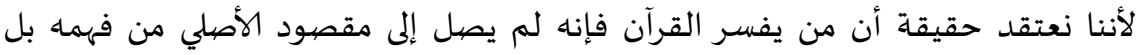
مستحيل الوصيول إلى الغاية.

وفي هذا الإطار أكد قري شهاب بأن الأمر بالقراءة في القرآن ليس مراده الفهم

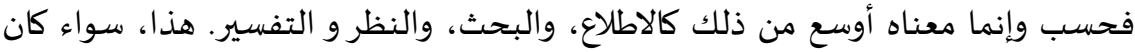
ما يتعلق بالآيات القرآنية القولية أو الآيات الكونية كما ورد في سورة العلق الآية الواحدة

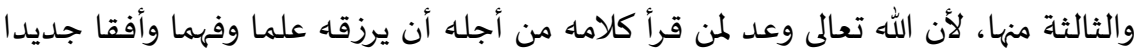
حتى ولو قرئ نفس الآيات 36. ثم أضاف قريش شهاب بأن ماوعده الله تعالى لعباده يكون حقيقة وذلك عندما يقرأون الآيات يجدون ألوانا متنوعة من التفسير أو آراء جديدة لم يسبق إليها. وهذا داديا دليل ظاهر على وجود بحوث جديدة على أسرار الكون، وذلك عندما تقرئ حقيقة الكونية 37 .

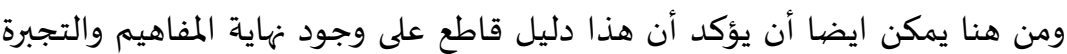
على معاني الآيات القرآنية منها الآيات الكونية التي لم تنقض وجودها. ومن هذا المنطلق

$$
\text { 35 35 المصيلدر السابق، } 14 .
$$
170.

${ }^{36}$ M. Quraish Shihab, Membumikan al-Qur'an (Bandung: Mizan, 1992),

$$
\text { 37 }
$$


يظهر وجوه إعجاز القرآن في أي مكان وزمان، حيث كلما يغوص معناه أضياء أنواره من كل جهاة، ويتفجر ينابيع مياه المعاني منها، حيث يكون منارا ومغذى للحياة. وليس من الخطأ أن يفسر أحد بتفسير العلميا لأن المراد منه الاكتشاف على عظمة قدرة الله تعالى من خلال الآيات الواردة سواء كانت مكتوبة في المصاحف أو مكتوبة في الكون. ومن هنا يرغب في اكتشاف الآيات القولية و اكتشاف الآيات الكونية سيزيد في الإيمان بالله والتقرب إليه تعالى بالنسبة لمن يكتشف لها ومن يقرأها. ومن ذلك يقول

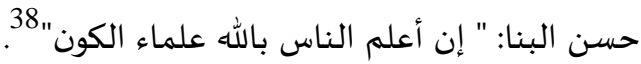
ولعل البحوث حول الآيات الكونية يعتبر مصدرا علميا ثانيا بعد البحوث عن الآيات

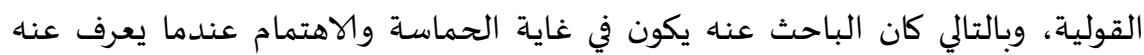
لأول لمسة الاكتشاف والاختراع عن معاني الآيات الكونية المشار إليها في القرآن. وهذا يعتبر من أهم شيء يهتم باء المهتم بمستقبل الأجيال القادماة.

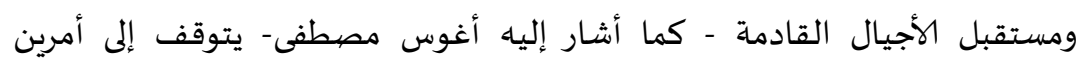

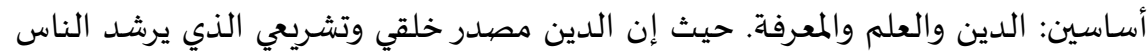
إلى الحياة بعد الممات، مع أن العلم والمعرفة الذي كان مصدره من الآيات القولية يحتاج إليه لوضع قواعد وأسس تجريبية ليكون دليلا على وقائع الحياة 39. ومن المستحسن من هذا أن نأخذ موقف المحايد من الآراء ونراعي كل تفسير الذي

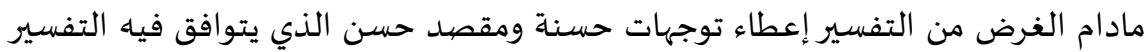
مع القواعد المقررة حيث إننا نقرأ وننظر مراد الله عز وجل بكل ما فينا من الطاقة المحدودة.

\section{الخاتمة}

$$
\text { يستخلص فيما سبق من المباحث أمور، وهي كمايلي: }
$$

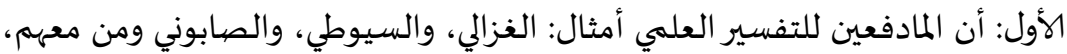
يرون أن النفسير للآيات الكونية من الأمور التي لها بالغة في الأهمية لاستكشاف وجوه إعجاز القرآن الكريم عما ثبت من تطور وتقدم العلوم والمعرفة التي وصلت إليه الأمة في

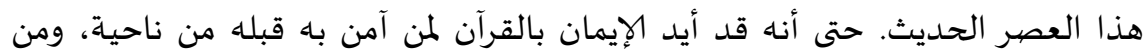

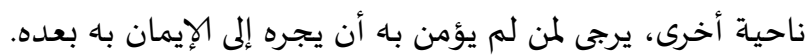

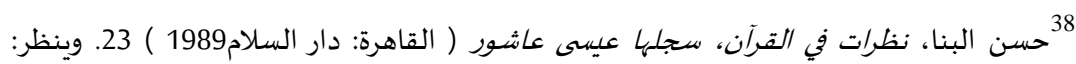

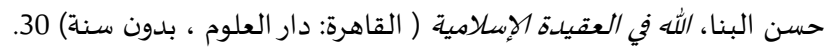
${ }^{39}$ Mustafa, Pusaran Energi..., 10. 
الثاني: وأما المعارضون للتفسير العلمي منهم: الشاطبي، والحسن البنا، وأمين الخولي ومن وافق معهم، يرون أن الهدف من نزول القرآن الكريم هو هداية البشرية فحسب، المباني،

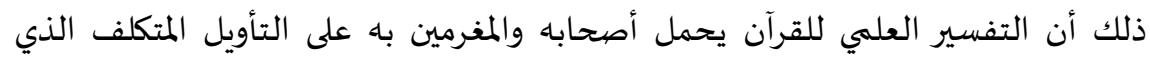

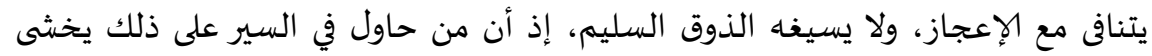
عليه في الخروج عما نزل القرآن من أجله.

الثالث: يظهر من خلال هذا المبحث وجه الاتفاق والاختلاف بين المخالفين والمدافعين

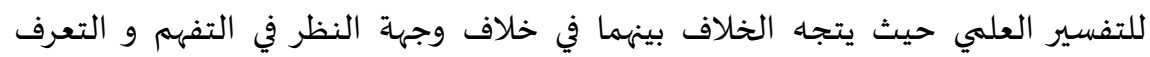

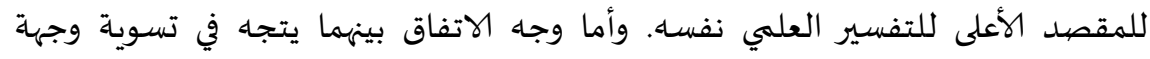
نظرهم في ايجاد كل آيات كونية هداية وهي هدى للناس جميعا.

\section{قائمة المراجع}

Elfandi, Muhammad Jamaluddin. 2004. Al-Qur'an tentang Alam Semesta, ter. Abdul Bar Salim. Jakarta: Sinar Grafika.

Faiz, Fakhruddin. 2011. Hermenentika al-Qur'an. Jogjakarta: Elsaq. Mustafa, Agus. t.th. Pusaran Energi Ka'bah. Surabaya: Padma Press.

Shihab, M. Quraish. 1992. Membumikan al-Qu'an. Bandung: Mizan.

ابن كثير، أبو الفداء. بدون سنة. تفسير القرآن العظيه، ج.2. سنقافورة-جدة: الحرمين.

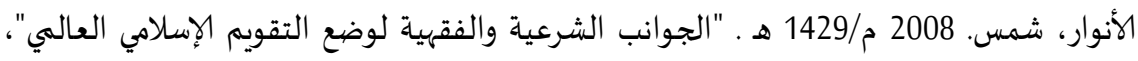
الجامعة مجلة الدراسات الإسلامية، النمرة 2.

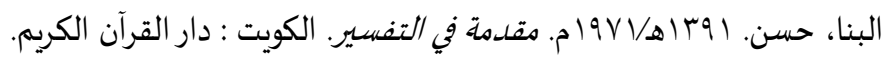
ل

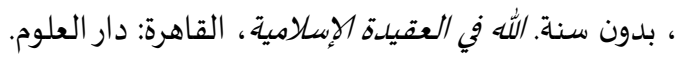

الخولي، أمين. 1995م. منهج التجديد في النحوي والبلاغة والتفسيروالأدب. القاهرة: الهيئة المصرية دارية

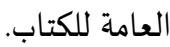

الذهبي، محمد حسين. 797 اهـ/9V7 م. التفسيروالمفسرون. بدون مكان النشر: بدون اسم النشر.

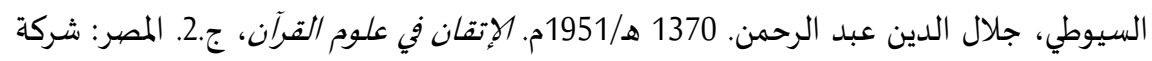
مكتبة الباب الحلبي. 
السيوطي، جلال الدين عبد الرحمن. بدون سنة. الإكليل فى استنباط التننيل. المصر: شركة مكتبة

$$
\text { البابي الحلبي. }
$$

$$
\text { الشرباصي، أحمد. 1962. قصية التفسير. القاهرة: دار القلم. }
$$

شريف، عدنان. 2004. من علم الفلك القرآني: الثوابت العلمية في القرأن الكريه. بيروت: دار العلم

$$
\text { للملايين. }
$$

الصابوني، محمد على. 1970. التبيان في علوم القرآن، بيروت: دار الإرشاد.

الغرناطي، أبو إسحاق إبراهيم بن موسى الشاطبي. 1341 هـ، ج. 2. الموافقات، بدون مكان النشر: دار

$$
\text { الفكر للطباعة والنشر والتوزيع. }
$$

الفزالي، أبو حامد محمد بن محمد. 1329 هـ . جواهر القرآن. كردستان: بدون اسم النشر. القطان، مناع. 1393 هـ/1973م. مباحث في علوم القرآن. بيروت: الشركة المتحدة للتوزع. 